\title{
Surface Changes in a Strain of Rhizobium trifolii on Mutation to Bacteriophage Resistance
}

\author{
By G. J. ATKINS \\ Department of Genetics, University of Liverpool \\ AND A. H. HAYES* \\ Department of Inorganic, Physical and Industrial Chemistry, \\ University of Liverpool, Liverpool, L69 $3 B X$ \\ (Received I March 1972; revised 5 May 1972) \\ SUMM A R Y

\begin{abstract}
A strain of Rhizobium trifolii and four phage-resistant derivatives had different mutation frequencies to phage resistance. One mutant adsorbed the phage to which it was resistant; the others showed little or no adsorption. Differences between the strains in the number and nature of ionizable surface groups were revealed by micro-electrophoresis. Two of the resistant mutants were lysed by lysozyme and three by lipase. Lysozyme + EDTA lysed all strains, but at different rates.
\end{abstract}

\section{INTRODUCTION}

Resistance to bacteriophage infection may be acquired by bacteria in three ways. The adsorption of bacteriophages to the bacterial surface may be prevented or penetration of the bacterial wall by bacteriophage nucleic acid may be inhibited. These two kinds of resistance involve changes in the bacterial wall (Weidel, 1958). The third kind of resistance involves the action of a restricting enzyme which degrades bacteriophage nucleic acid after injection (Molholt \& Fraser, 1965).

The walls of a few strains of Rhizobium trifolii have been partially analysed. Humphrey \& Vincent (1962) found mucopeptide components, glucose, rhamnose and a high proportion of amino acids in the wall of one strain. Humphrey \& Vincent (I969a) have also studied the serological properties of the somatic $\mathrm{O}$ antigens from two other strains of $R$. trifolii. Both antigens showed components characteristic of both normal lipopolysaccharide (LPS) structures and also of the capsular $\mathrm{K}$ antigens which occur in certain Gram-negative bacteria. Marshall (1966) studied the electrophoretic behaviour of some fast- and slow-growing strains of Rhizobium. With one exception, the slow-growing strains had only carboxyl groups, whereas the fast-growing strains had both carboxyl and amino groups in the surface. Humphrey \& Vincent ( $1969 b$ ) reported that the LPS antigens from two strains of $R$. trifolii showed relative mobilities (from immuno-electrophoresis) similar to those found for whole bacteria. It was suggested that the surface charge characteristics of these two strains were determined by the structures and compositions of the LPS antigens.

Most phage-resistant mutants in Eschericha coli acquire resistance by preventing phage adsorption (Weidel, I958). This paper investigates the surface of a strain of Rhizobium trifolii and four rhizobiophage-resistant derivatives.

* Present address: Brooke Bond Liebig Research Centre, Sonning Common, Reading, Berkshire. 


\section{METHODS}

Phage and bacteria. Phages e and $\mathrm{c}$ were originally isolated from soil and form large, clear plaques on susceptible bacteria. The bacterial strains used are all derivatives of the noncapsulated strain WI9 isolated from the natural environment. WI9/c is a bacterial strain selected for resistance to phage c. WI9/eI and wi9/e2 were selected for e resistance, but differ in their pattern of susceptibility to other bacteriophages. WI $9 / \mathrm{ch}$ was obtained by selecting for resistance of WI9 to a host-range mutant of phage $\mathrm{c}$ able to grow and form plaques on $\mathrm{WI} 9 / \mathrm{c}$.

Bacteria were grown in the medium designated GS-YC by Schwinghamer (1960), with the exception that glucose was incorporated at $0 . \mathrm{I} \%$ to reduce gum formation. For all experiments, bacterial cultures were harvested in late exponential growth phase (bacterial concentration about $2 \times 10^{8} / \mathrm{ml}$ ).

Phage lysates were prepared by inoculating an exponentially growing bacterial culture with a single phage plaque and usually contained ${ }^{1} \mathrm{O}^{10}-\mathrm{IO}^{11}$ plaque-forming units (p.f.u.) $/ \mathrm{ml}$.

Mutation to phage resistance. A viable count was first performed on a bacterial culture in exponential growth phase. This culture was then infected at high multiplicity by a phage strain in liquid culture for a period of $30 \mathrm{~min}$. The bacteria were then plated and resistant colonies counted. The average proportion of resistant bacteria in five independent cultures was recorded as the mutation frequency.

Adsorption constants. These were measured as described by Adams (1959). After the addition of phage to bacteria, unadsorbed phage were measured at intervals.

Micro-electrophoresis. Electrophoretic mobilities were determined as described by Douglas, Ruddick \& Williams (1970). Bacterial suspensions were prepared for electrophoresis by $3 \times$ centrifugation and resuspension in $0.05 \mathrm{M}-\mathrm{NaCl}$ at a concentration of about $5 \times 10^{9}$ organisms $/ \mathrm{ml}$. For each mobility determination, $\mathrm{I} \mathrm{ml}$ of this suspension was added to $99 \mathrm{ml}$ of the appropriate buffer solution (Douglas et al. 1970).

Reagents. $p$-Toluene sulphonyl chloride (PTSC) was recrystallized from petroleum ether and used as a saturated solution in phosphate buffer, $\mathrm{pH} 7$. Washed $(3 \times)$ bacteria were treated for $\mathrm{I} \mathrm{h}$ at $4{ }^{\circ} \mathrm{C}$, washed $3 \times$ in Michaelis $\mathrm{pH} 7$ buffer, and finally resuspended in Michaelis buffer. Bacteria which had been subjected to the same procedure in the absence of PTSC were used as controls.

Sodium dodecyl sulphate (SDS) was used as described by Douglas et al. (1970).

Enzyme treatments. Lipase (wheat-germ; British Drug Houses (B.D.H.), Godalming, Surrey) was used at 500 p.p.m. in Michaelis $\mathrm{pH}_{7}$ buffer. Lysozyme (egg-white; B.D.H.) was used at 50 p.p.m. in Michaelis $\mathrm{pH}_{7}$ buffer. Lysozyme was also used at 50 p.p.m. in $0.05 \mathrm{M}$-ammonium acetate $+\mathrm{r} \cdot 0 \mathrm{mM}$-ethylenediamine-tetra-acetic acid (EDTA). All enzyme treatments were carried out at $25^{\circ} \mathrm{C}$. Exponentially growing bacteria were washed $3 \times$ by centrifugation and finally resuspended at about $5 \times 10^{8} / \mathrm{ml}$ in the appropriate enzyme solution. The change in extinction of each suspension was determined at intervals.

\section{RESULTS}

Phage-resistant mutants obtained. The proportion of bacteria resistant to phage e in cultures of WI9 was approximately Ioo times that of bacteria resistant to phage c (Table I). Also, the frequency of e resistant bacteria in WI9/c cultures was approximately the same as in WI9 cultures. However, no mutants of wi9/e I or wi9/e2 resistant to c were observed. Only one WI $9 /$ ch resistant mutant colony was isolated. 
Table I. Frequency of phage resistant bacteria in cultures of each strain

$\begin{array}{lcc}\text { Strain } & \begin{array}{c}\text { Frequency of resistance } \\ \text { to phage } \mathrm{c}\end{array} & \begin{array}{c}\text { Frequency of resistance } \\ \text { to phage e }\end{array} \\ \text { WI9 } & 2 \cdot \mathrm{I} \times 10^{-7} & 2.2 \times 10^{-5} \\ \text { WI } / \mathrm{C} & - & \mathrm{I} \cdot 4 \times 10^{-5} \\ \text { WI9/eI } & <10^{-8} & - \\ \text { WI9/e2 } & <10^{-8} & -\end{array}$

Table 2. Adsorption constants of phages $c$ and e to sensitive and resistant bacteria

$\begin{array}{cc}\text { Phage } & \text { Bacterial strain } \\ \mathrm{c} & \text { WIg } \\ & \text { WI } 9 / \mathrm{c} \\ & \text { WI } 9 / \mathrm{ch} \\ \text { WI } 9 / \mathrm{eI} \\ \text { WI } 9 / \mathrm{e} 2 \\ \text { WI } \\ \text { e } & \text { WI } 9 / \mathrm{c} \\ & \text { WI } 9 / \mathrm{ch} \\ & \text { WI } 9 / \mathrm{eI} \\ \text { WI } 9 / \mathrm{e} 2\end{array}$

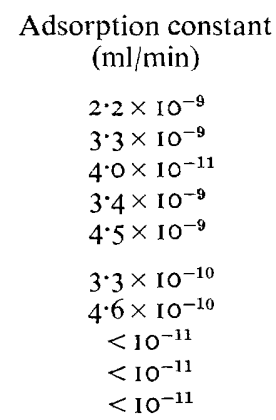

No lysis was observed when supernatants from cultures of any of the phage-resistant mutants were plated with WI9. It is therefore unlikely that any of the phage-resistant mutants are lysogenic for phages $\mathrm{c}$ or $\mathrm{e}$.

Adsorption constants. These results are summarized in Table 2. Phage c adsorbed to wI9 at a faster rate than phage e. However, although phage $\mathrm{c}$ adsorbed to wig/er and wi9/e2 at essentially the same rate as to w I9, phage was not adsorbed to these two mutant strains. Similar constants were found for the adsorption of phage e to both WI 9 and wi $/ \mathrm{c}$; phage c also adsorbed to WI9/c at a similar rate to WI9, although resistance was still maintained. No detectable adsorption of phage e to WI9/ch was found, and adsorption of phage c was much slower than to wig or wig/c.

Micro-electrophoresis. All strains lysed to varying degrees at $\mathrm{pH}$ values greater than 9 , and hence mobilities could not be measured at higher $\mathrm{pH}$ values. The mobility versus $\mathrm{pH}$ curves showed differences between strains (Fig. I). Only wig had fairly strong acidic groups. WI9/c and WI9/e2 gave similar mobility versus $\mathrm{pH}$ responses, as did wig/ch and WI9/er. These latter two strains showed substantial positive mobilities at $\mathrm{pH} 2 \cdot 0$.

The mobility shifts obtained on treatment with PTSC and SDS are shown in Table 3. WI9 showed substantial shifts after treatment with both reagents, indicating that both surface amino groups and surface lipid are present. wr9/c and W I9/e2 showed only small shifts after PTSC treatment, indicating low frequencies of amino groups in both bacterial surfaces. These strains gave heterogeneous mobility distributions from individual organisms after SDS treatment. This unusual finding suggests non-uniform surface lipid contents within the populations for these two strains. Substantial shifts were obtained for WI9/ch and wr9/eI with SDS, but whereas wi9/ch showed only a small shift with PTSC, wi9/e I gave a large shift after treatment with this reagent.

Enzyme treatments. The decrease in extinction of bacterial suspensions during incubation with lipase, lysozyme and lysozyme + EDTA are shown in Fig. 2. wi9 only showed a significant decrease in extinction when treated with lysozyme +EDTA; lipase and lysozyme 


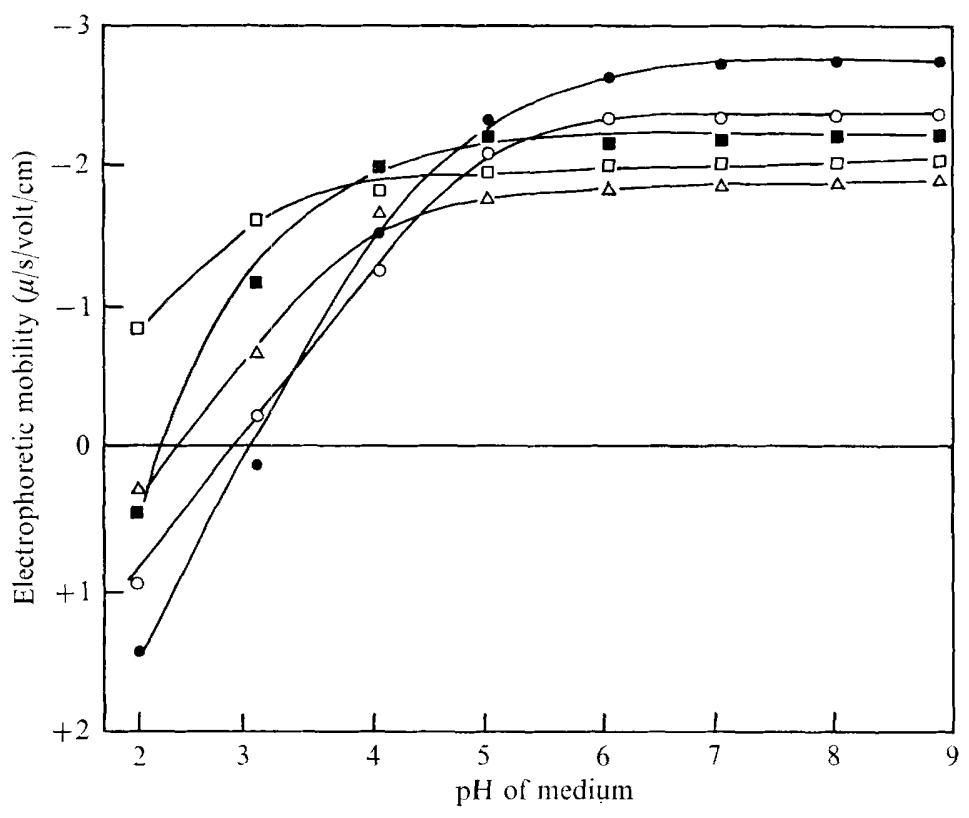

Fig. I. Electrophoretic mobility versus $\mathrm{pH}$ for Rhizobium trifolii wI9 and four phage-resistant mutants of this strain. $-\square-\square-$, wig; $-\square-\square-$ WI9/c; $-\mathrm{O}-\mathrm{O}-$, wI9/ch; WI9/eI; $-\triangle-\triangle-$, wI9/e2.

Table 3. Electrophoretic mobilities of bacterial strains before and after chemical treatments

\begin{tabular}{lccc} 
& \multicolumn{3}{c}{ Mobilities $(\mu / \mathrm{s} / \mathrm{volt} / \mathrm{cm})$} \\
Bacterial strain & $\begin{array}{c}\text { Michaelis } 7 \\
\text { buffer alone }\end{array}$ & SDS* & PTSC $\dagger$ \\
WI9 & -2.06 & -2.94 & -2.47 \\
WI9/c & -2.2 I & Heterogeneous & -2.44 \\
WI9/eI & -2.73 & -3.15 & -3.36 \\
WI9/e2 & -2.04 & Heterogeneous & -2.18 \\
WI9/ch & -2.47 & -3.08 & -2.53
\end{tabular}

* Mobilities were determined in Michaelis pH 7 buffer with $1 \cdot 0 \mathrm{~mm}$-SDS.

$\dagger$ Mobilities were determined in Michaelis $\mathrm{pH}_{7}$ buffer after treatment with excess PTSC.

alone had only a small effect. This indicates a normal type of Gram-negative wall structure.

Lipase produced some lysis of wr9/ch, WI9/eI and WI9/e2, but not WI9/c. Hence it is possible that the surface lipid in these first three strains may have a structural role in the walls. This may be due to alterations in the organization of wall polymers such that the underlying mucopeptide layer is disturbed.

Lysozyme attacked w I $9 / \mathrm{ch}$ in conjunction with EDTA or in buffer alone and considerably aggregated WI9/er. The decrease in extinction for this strain was therefore not directly related to lysis. These results suggest the presence of some exposed mucopeptide in the bacterial surfaces. Lysozyme + EDTA lysed all the bacterial strains, but WI9/c and WI9/e2 were lysed significantly slower than the other strains. 


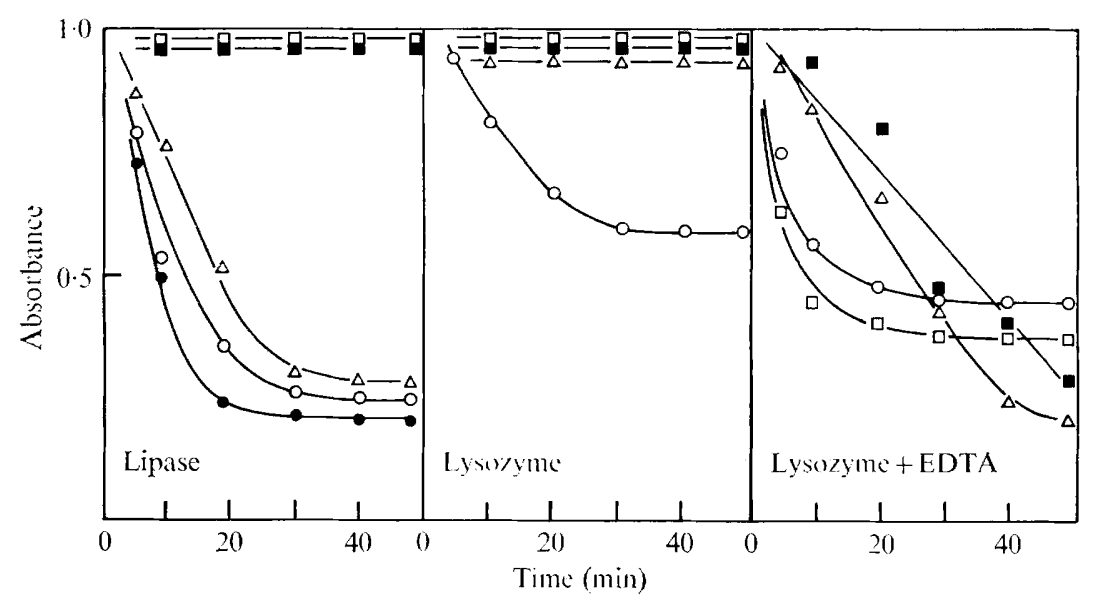

Fig. 2. Decrease in extinction of bacterial cultures during enzyme treatment. Lysozyme produced cellular aggregation for wig/eI. - $\square-\square-$, WI9; - - - - , wI9/c; - $-0-$, WI9/ch; - wig/e1; $-\triangle-\triangle-$, wig/e2.

\section{DISCUSSION}

The electrophoretic mobility of strain wig suggests that carboxyl and possibly also phosphate groups are present on the organism surface. Stronger acidic groups are indicated for this strain than for any of the phage-resistant mutants. Lysis of Gram-negative bacteria by lysozyme + EDTA, as found for WI9, has been observed previously (Asbell \& Eagon, I966; Gray \& Wilkinson, 1965). The mechanism is thought to involve chelation of divalent cations present in the wall and hence disturbance of structures which normally shield the mucopeptide substrate.

The changes bringing about phage resistance in the mutants derived from w I 9 are likely to arise from alterations in the composition or organization of cell wall polymers. These changes probably affect the outer layers of LPS and lipoprotein which are linked to and overlie the mucopeptide layer. In wi9/c, a small change in cell wall composition, which does not drastically alter the overlying layers, is indicated. Hence both phages can still adsorb to this mutant. The change does, however, apparently render the mucopeptide layer less susceptible to the action of lysozyme. Lysozyme may be a component of some bacteriophages and may be involved in phage penetration (Barrington \& Kozloff, 1956). Possibly the changed surface of wi $9 / \mathrm{c}$ inhibits penetration of phage $\mathrm{c}$ by rendering its lysozyme ineffective.

The differences found for WI9/eI and W19/e2 probably reflect greater alterations in surface composition so that phage e can no longer adsorb to either mutant. Furthermore, lipid in the outer layers appears to have some structural properties, possibly because of altered underlying mucopeptide.

The changes resulting from the wig/ch mutation probably involve considerable abnormalities in wall structure. In consequence, the primary receptor sites for both phage e and phage $\mathrm{c}$ are largely destroyed.

The authors wish to thank Dr B. M. Faulkner and Dr H. W. Douglas for their advice and helpful criticism. One of us (G.J.A.) is supported by a Science Research Council research studentsinip. 


\section{REFERENCES}

Adams, M. H. (1959). Bacteriophages. New York: Interscience Publishers.

AsBell, M. A. \& EAGON, R. G. (I966). The role of multivalent cations in the organisation and structure of bacterial cell walls. Biochemical and Biophysical Research Communications 22, 664-67I.

Barrington, L. F. \& KozLoff, L. M. (1956). Action of bacteriophage on isolated host cell walls. Journal of Biological Chemistry 223, 615-627.

Douglas, H. W., RudDick, S. M. \& Williams, S. T. (1970). A study of the electrokinetic properties of some actinomycete spores. Journal of General Microbiology 63, 289-295.

Gray, G. W. \& WiLKInson, S. G. (1965). The effect of ethylenediaminetetra-acetic acid on the cell walls of some Gram-negative bacteria. Journal of General Microbiology 39, 385-399.

Humphrey, B. A. \& Vincent, J. M. (1962). Calcium in cell walls of Rhizobium trifolii. Journal of General Microbiology 29, 557-561.

Humphrey, B. A. \& Vincent, J. M. (I969a). The somatic antigens of two strains of Rhizobium trifolii. Journal of General Microbiology 59, $41 \mathrm{I}-425$.

Humphrey, B. A. \& VINCENT, J. M. (1969 $b$ ). Correlation between the surface charge density of whole cells and electrophoretic movement of isolated somatic antigens of Rhizobium trifolii. Journal of Bacteriology $98,845-846$.

MARSHALL, K. C. (1966). Electrophoretic properties of fast and slow-growing species of Rhizobium. Australian Journal of Biological Sciences 20, 429-438.

Molholt, B. \& Fraser, D. (1965). Reversal of restriction for host-modified T2 and T4 DNA upon conversion of non-permissive Escherichia coli to spheroplasts. Biochemical and Biophysical Research Communications 19, 571-575.

SCHWinghamer, E. A. (1960). Studies on induced variation in the rhizobia I. Defined media and nodulation test techniques. Applied Microbiology 8, 349-352.

WeIDEL, W. (I958). Bacterial viruses (with particular reference to adsorption/penetration). Annual Review of Microbiology 12, 27-48. 